\title{
Ein neues Gesetz ist nötig - und möglich
}

Die FMH - und damit die Schweizer Ärzteschaft - unterstützt das neue IVGesetz, wie es Bundesrat und Parlament mit der 5. Revision vorschlagen. Dies hat die Delegiertenversammlung der FMH beschlossen, die am 18. April 2007 in Bern tagte.

«Eingliederung statt Rente» und eine bessere Fallbetreuung: Das sind die beiden Hauptziele der Revision - die FMH stellt sich dahinter und auch hinter den vorgezeichneten Weg, wie sie erreicht werden sollen.

Die DV der FMH hat damit die positiven, integrationsfördernden Elemente der Vorlage Früherkennung, Frühintervention und die Möglichkeit von Einarbeitungszuschüssen - höher gewichtet als die Passagen im Gesetz, die vom falschen Generalverdacht der sogenannten «Scheininvaliden» durchtränkt sind.
Grosse Bedenken bestehen in der FMH bezüglich der im Gesetz angelegten weiteren Aufweichung des Arztgeheimnisses - und dies ist im Vorfeld dieses Entscheids der Delegierten unter anderem in den Medien auch so kommuniziert worden.

Die FMH verlässt sich darauf, dass die Ärztinnen und Ärzte der regionalen Dienste der IV verantwortungsvoll mit ihrer umfassenden Vollmacht umgehen werden, insbesondere in der Definition, welche Informationen und Unterlagen die behandelnden Ärzte herausgeben müssen.

La FMH - et donc le corps médical suisse - va soutenir la nouvelle loi sur l'assurance-invalidité proposée par le Conseil fédéral et le Parlement dans le cadre de la $5^{\mathrm{e}}$ révision de l'Al. Ainsi en a décidé l'Assemblée des délégués (AD) de la FMH, qui a siégé le 18 avril 2007 à Berne.

La «réadaptation plutôt que la rente» et une meilleure gestion des cas: la FMH soutient ces deux objectifs essentiels de la révision de l'AI et approuve finalement la voie qui est tracée pour les atteindre.

L'AD de la FMH a ainsi donné plus de poids aux éléments positifs du projet qui favorisent l'intégration - dépistage et intervention précoces et possibilité de percevoir des allocations d'initiation au travail - qu'aux passages de la loi qui sont imprégnés d'un soupçon généralisé - et erroné - d'abus à l'égard de soi-disant «faux invalides».
La FMH éprouve de très sérieuses réserves quant au nouvel affaiblissement du secret médical que renferme cette loi. Elle a fait part de ses craintes à cet égard, entre autres par le biais des médias, avant même que les délégués ne rendent leur décision.

La FMH compte sur les médecins des services régionaux de l'AI pour qu'ils fassent un usage responsable du large pouvoir qui leur sera conféré pour définir les informations et documents qui doivent être remis par les médecins traitants. 